\title{
Intrapersonal and community factors associated with prostate cancer screening among African-American males in the US
}

This article was published in the following Dove Press journal:

Nursing: Research and Reviews

28 September 2016

Number of times this article has been viewed

\author{
Sabrina L Dickey' \\ Eileen Cormier' \\ James Whyte IV' \\ Penny A Ralston ${ }^{2}$ \\ 'College of Nursing, ${ }^{2}$ Center \\ on Better Health and Life for \\ Underserved Populations, Florida \\ State University, Tallahassee, FL, USA
}

Purpose: The purpose of this research was to examine intrapersonal and community factors associated with prostate cancer screening (PCS) among African-American (AA) males of $\geq 40$ years from a nationally representative data set in the US. The theory of planned behavior was utilized as the theoretical framework.

Patients and methods: A cross-sectional secondary analysis employed data from the National Health and Nutrition Examination Survey in the US. The sample consisted of 377 AA males. The primary outcome variables were two PCS tests, the digital rectal exam (DRE) and the prostate-specific antigen test. Logistic regression models were developed to test for associations between the PCS tests and the factors of interest.

Results: The factors of age, education, and access to a health care facility were associated with AA males receiving the DRE. The age group of 40-49 years was least likely to receive the DRE when compared to the age group of $\geq 70$ years. Similarly AA males without a college degree were also least likely to receive the DRE when compared to AA males with a college degree. AA males with access to health care were more likely than those without access to receive the DRE. Age $<70$ years along with church attendance was associated with AA males receiving the prostate-specific antigen test.

Conclusion: Differences were present for significant associations among intrapersonal and community variables and the two PCS exams. A culturally sensitive approach is necessary for understanding factors associated with PCS among AA males, which is central to designing and appropriately targeting public health interventions to decrease the health disparity of prostate cancer among this high-risk population.

Keywords: prostate cancer screening, prostate cancer, African-American, intrapersonal, community, theory of planned behavior

\section{Introduction}

Prostate cancer $(\mathrm{PCa})$ is the third most common type of cancer in the US with 220,880 estimated new cases in 2015. Additionally, PCa accounts for 13.3\% of all new cancers and it was estimated to cause 27,540 deaths in the US. ${ }^{1}$ Worldwide, there were $\sim 899,000$ incidences of PCa and 258,000 deaths from PCa that occurred in 2008. ${ }^{2}$ From an international perspective, $\mathrm{PCa}$ ranks fourth as the most common cancer among males and females. ${ }^{3}$ Additionally, it is the second most common cancer among males worldwide and it accounts for $15 \%$ of all cancers occurring among males. ${ }^{3}$ In 2012 , PCa was the fifth leading cause of death at 307,000 worldwide. ${ }^{3}$ In general, mortality rates from PCa were high in the Black populations of the Caribbean and sub-Saharan Africa, 29 per 100,000. ${ }^{3}$
Correspondence: Sabrina L Dickey College of Nursing, Florida State University, 98 Varsity Way, Tallahassee, FL 32306-43 I0, USA

$\mathrm{Tel}+\mathrm{I} 8506445620$

Fax+I 8506447660

Email sldickey@fsu.edu 
It has long been recognized that African-American (AA) males have a higher risk of developing PCa and their mortality from the disease is markedly higher 214.5 per 100,000 compared to all races 137.9 per $100,000 .^{1-4}$ AA males are also more likely to be diagnosed with PCa at an advanced stage, which contributes to poor treatment outcomes. ${ }^{5} \mathrm{PCa}$ mortality has been linked to low rates of prostate cancer screening (PCS) among AA males. ${ }^{6}$ However, AA males are less likely to receive $\mathrm{PCa}$ screening or engage in preventive health behaviors. ${ }^{7,8}$

Current standards of care in the US reflect a great deal of variability in recommended approaches to PCS. For example, the American Cancer Society advises that asymptomatic males have the opportunity to make an informed decision about screening for $\mathrm{PCa}$ after they receive information about the uncertainties, risks, and potential benefits associated with PCS. ${ }^{9}$ The American College of Preventive Medicine, conversely, states there is insufficient evidence to recommend for or against routine screening utilizing the digital rectal exam (DRE) or prostate-specific antigen (PSA) test. Likewise, PCS guidelines from the United States Preventive Services Task Force recommend against annual screening. The United States Preventive Services Task Force claims that screening causes more harm than benefit due to the performance of unnecessary surgeries. ${ }^{10}$ While evidence for and against PCS is inconsistent, current guidelines fail to address racial and ethnic disparities associated with PCa, and hence, potentially adverse consequences of discontinuing testing for high-risk groups such as AA males. ${ }^{11}$ The research used to develop the current guidelines lacked sufficient numbers of AA and other racial/ethnic minorities. ${ }^{12,13}$ The purpose of the study is as indicated in the next paragraph.

The purpose of this research was to examine intrapersonal and community factors associated with PCS among AA males $\geq 40$ years from a nationally representative data set in the US. The theory of planned behavior (TPB) was utilized as the theoretical framework.

\section{Theoretical framework}

The theoretical framework guiding the current study is Ickek Ajzen's TPB. The TPB surmises behavior occurs as a result of an individual's beliefs and their intention to perform the behavior. The TPB that aligns with the current study is based on its concepts of internal and external beliefs, which assist with explaining and predicting behavior. ${ }^{14}$ Previous studies regarding PCS utilized the TPB based on the concept of an individual's intention being associated with an increased rate of receiving PCS. ${ }^{15}$

The TPB consists of three constructs otherwise known as the following beliefs: behavioral beliefs, normative beliefs, and control beliefs. It is the beliefs, which exert the influence on an individual's behavior. Within the constructs are the factors of attitude, subjective norms, and perceived behavioral control that influence behavior. ${ }^{14}$ The construct of attitude encompasses various psychological concerns AA males may encounter when faced with the decision to receive PCS. Some of the psychological concerns which can influence the attitude of AA males to receive PCS are anxiety, stigma, and masculinity. Generally, the decision to receive PCS can cause AA males to consider facing a possible diagnosis of PCa and risk feelings of fear and shame. ${ }^{16}$ Fortunately, the PSA test has alleviated some feelings of discomfort or impingement on their masculinity as seen with the DRE. Masculinity and the accompanying fear of appearing vulnerable can also influence a man's perception of health risks. ${ }^{17}$ In fact, an increased sense of masculinity is associated with an increase in one's health risks. ${ }^{17}$ Therefore, males who adhere to a traditional household belief system may not pursue health services for screening or view themselves as being at risk for acquiring diseases such as cancer. Within the current study the variables associated with attitude and $\mathrm{PCa}$, anxiety, stigma, and masculinity were not present in the National Health and Nutrition Examination Survey data set.

The factors of subjective norms and perceived behavioral control were examined in the current study. Subjective norms are considered one's knowledge and their perception of social pressure to perform a behavior. Therefore, age, education, and the spouse of the AA males in the current study are incorporated as their subjective norm and a potential influence for the AA males to receive PCS. Expectations from a spouse or family member to engage in PCS has been indicated as a motivator for AA males to engage in PCS. ${ }^{18}$ Similar findings indicated that seeking advice from family members was a trait of AA males. ${ }^{19}$ Seeking advice and acknowledging expectations from spouse and family members are just a few examples of subjective norms AA males encounter for receiving PCS. Religion also has the potential to create social normative pressure to engage in PCS. In fact, religion provided an inclination to participate in $\mathrm{PCS}^{20}$

Additionally, perceived behavioral expectations are those which arise from the individual's social groups identified as spouses, family members, friends, and neighbors. ${ }^{14}$ The influence of perceived behavioral control is also reported in the literature as a significant predictor for AA males to receive PCS. ${ }^{21}$ Within the current study, perceived health status was indicated as an example of perceived behavioral control. Intrapersonal factors, such as income corresponds with how an individual views their perceived behavioral control. ${ }^{21}$ 
The presence of resources, access to health care, combined with an adequate income empower AA males to engage in the PCS as a health promotion behavior. The influence of subjective norms was also evident in previous literature that indicated PCS was predicted by individuals that were nonattenders and irregular attenders of church. ${ }^{22}$ Intention to engage in PCS was also found to influence whether or not AA males received a PCS. ${ }^{15}$ AA males may expect a behavior to occur when they are exposed to a barrage of information from various social groups regarding the need for PCS. ${ }^{23}$

\section{Intrapersonal factors}

Age and education

Literature exists from various studies regarding correlates of factors for receiving PCS. However, there was limited data from studies that utilized a national data set to examine the health behaviors of AA males. Literature suggests that, in general, males over the age of 50 years are most likely to receive PCS, including AA males. ${ }^{24,25}$ Higher levels of education, such as a college degree or higher, has also been reported to be positively correlated with receiving PCS among AA $\operatorname{men}^{7,26}$ though this association has not been consistently demonstrated ${ }^{24,27}$ Evaluations of educational programs aimed at increasing PCS (DRE or PSA test) nonetheless suggested that educational level can be an important determinant of how informational material on PCa and PCS is accessed and understood. ${ }^{28}$

\section{Income}

Income level has also been reported to play an important role in determining whether AA males receive PCS. ${ }^{6}$ AA males who earn higher incomes are more likely able to afford health insurance, have access to preventive health information and services, and receive PCS. ${ }^{15,27}$ AAs in general are at risk for limited access to health care services that include preventive and health promotion services. ${ }^{29}$ Not surprisingly, lack of a consistent health care provider and access to services that promote and provide PCS have been identified as formidable barriers to AA males receiving PCS. ${ }^{30-33}$

\section{Perceived health status}

Qualitative research involving AA males suggested that selfawareness of good health and well-being were motivators to receive PCS. ${ }^{27,34}$ Tannor and $\operatorname{Ross}^{35}$ found that AA males receiving a PSA test within the past year reported good health. Literature indicated AA males, which rated their health as good/excellent may engage in PCS as a health promoting behavior. ${ }^{36}$

\section{Marital status}

There is tangible support for marital status being associated with AA males receiving PCS. Drake et $\mathrm{al}^{24}$ found that $88 \%$ of AA males who were married were more likely to receive PCS. Satia and Galanko ${ }^{26}$ identified marital status as a statistically significant factor for receiving PCS. Further, the literature supports wives as a central influence for males to receive $\mathrm{PCS} .{ }^{3,15}$

\section{Community factors Church attendance}

Community factors such as access to a church in the neighborhood has also been identified as a key component of outreach for AA males. ${ }^{37,38}$ AAs are more likely to attend religious services and activities compared to other races ${ }^{39,40}$ and church attendance has been shown to be associated with informational support regarding PCS and higher levels of PCS. ${ }^{3,18,20}$ Churches are well-recognized as vital community resources for social support and health promotion, and hence, conduits to reducing health disparities in this population. ${ }^{29,41-44}$

\section{Access to health care}

Receiving consistent health care and a lack of transportation are barriers that many AAs have encountered. ${ }^{45}$ Likewise, the lack of health insurance as well as the cost for PCS have been identified as primary barriers to receiving PCS. ${ }^{46}$ It is unfortunate that a lack of health facilities and educational awareness regarding $\mathrm{PCa}$ may be viewed as barriers to receiving PCS as well as additional health promotion and preventive services. ${ }^{29}$ Talcott et $\mathrm{al}^{32}$ reported AA males as being less likely to access and receive a consistent source of health care. Nonconventional venues within the community, such as barber and beauty salons are being utilized to provide education on PCa and actual PCS.

\section{Methods}

The current study was performed from a secondary data analysis after obtaining approval from the Florida State University Institutional Review Board. The population-based secondary analysis employed the public use data set from the Centers for Disease Control and Prevention's National Health and Examination Survey (NHANES). NHANES is a nationally representative, cross-sectional data set collected by the National Center for Health Statistics. Diversity within the NHANES data set was achieved by over-sampling for AA, Hispanic, and males $>60$ years of age. An interdisciplinary team (physicians, medical and health technicians, and dietary/health interviewers) conducted the survey. Participants completed questionnaires in a Mobile 
Examination Center utilizing a computer-assisted personal interview and an audio-computer-assisted self-interview.Participants signed a consent prior to participation in the NHANES study and inclusion in the NHANES data set.

\section{Sample}

The NHANES studies began in 1960s wherein surveys are conducted regarding the health and nutrition of adults and children throughout the US. It is a public data set without any participant identifiers and it is provided by the Centers for Disease Control and Prevention. The health needs of the nation guide the types of surveys that will be implemented in studies that occur on an annual basis. A unique characteristic of the NHANES studies is that they oversample for minorities and they collect interviews as well as physical examinations. The pooled sample from the selected NHANES data set which contained data for the DRE and the PSA test was the cohort of 2007-2008 and consisted of 10,149 participants, of which 2,211 were AA. Inclusion criteria for the current study included AA males $\geq 40$ years. Power analysis prior to data analysis using a significance level of $0.05,80 \%$ power, and an effect size of 0.20 indicated a minimum of 307 participants were required for the study. After excluding AA males that were $<40$ years of age, the sample for the current study went from 2,211 to the final sample of 377 .

\section{Variables \\ Outcome variables}

The primary outcome variables were two PCS tests, the DRE and the PSA test. The DRE was measured with the question, "Have you ever had a rectal examination to check for prostate cancer?" Responses to the question were coded as 0 (no) or 1 (yes). The PSA test measure was based on the number of actual blood tests completed; participants were given the option to receive a PSA test when the survey was conducted. Participants who refused to have the PSA test were coded within the current study as 0 (no) and those who received the PSA test were coded as 1 (yes). Participants were offered to receive the PSA test during the survey. Participants, who were elected to receive the PSA test, received the test in the Mobile Examination Center.

\section{Independent variables}

Intrapersonal and community variables included in the analysis were: age, education level, income, perceived health status, marital status, church attendance, and access to health care. Participants' age for the current study was partitioned out of the NHANES data set and categorically listed as 40-49, $50-59$, and $>60$ years. Educational level (categorical; $<9$ th grade, 9-12th with no diploma, high school diploma/general education diploma, some college, and college graduate) was also split into two categories as (noncollege graduate and college graduate) due to the majority of participants who did not have a college degree. All categories of income level (<\$20,000, \$20,000-\$44,999, \$45,000-\$74,999, and $\geq \$ 75,000)$ were included in the analysis. Self-reported perceived health status (categorical, excellent, very good, good, fair, and poor) was determined, by the question, "Would you say your health in general is...?"

Church attendance (continuous) was assessed by asking participants, "How often do you attend church or religious services?" and was entered as the number of times per month. Access to health care (categorical) was assessed by asking, "Is there a place that you usually go when you are sick or need advice about your health?" (there is one place to go for advice, there is no place to go for advice, and there is more than one place to go for advice). This variable was collapsed into two categories 0 (no routine health facility to access) and 1 (yes there is a routine health facility to access).

\section{Statistical analysis}

The Statistical Program for the Social Sciences (version 20, IBM Corporation, Armonk, NY, USA) was used to process descriptive statistics and logistic regression models. Binary logistic regression allowed for estimation of the likelihood of receiving PCS and assessing the association of intrapersonal and community factors with PCS. Before conducting the regression analysis, multicollinearity was assessed. Correlation analyses using Pearson's $r$ were computed for all the variables. There were no correlation coefficients $>0.6$ suggesting multicollinearity was not an issue. Two multivariate models were developed to address the aims of the study. The DRE and PSA test were regressed separately on each set of intrapersonal and community factors. Therefore, there were two separate models for the current study, which analyzed the outcome variables of the DRE and the PSA test. A $P$-value of $<0.05$ was considered to be statistically significant. The Hosmer and Lemeshow test (goodness of fit test statistic) was used to establish if each regression model was correctly specified. A $P$-value of $>0.05$ represents a good fit.

\section{Results Descriptive}

Descriptive statistics are presented in Table 1 as the overall mean, standard deviation, percentages, minimums, and maximums. The 377 participants ranged in age from 40 to 80 years $(\mathrm{M}=59)$; the majority were 50 years older 
Table I Descriptive statistics $(n=377)$

\begin{tabular}{|c|c|c|c|c|}
\hline Variable & $(\%)$ & SD & Min & Max \\
\hline \multicolumn{5}{|l|}{ Prostate cancer screening } \\
\hline \multicolumn{5}{|l|}{ Digital rectal exam } \\
\hline No & 30.2 & & & \\
\hline Yes & 69.8 & & & \\
\hline \multicolumn{5}{|l|}{ Prostate-specific antigen test } \\
\hline No & 22.5 & & & \\
\hline Yes & 77.5 & & & \\
\hline \multicolumn{5}{|l|}{ Controls } \\
\hline \multicolumn{5}{|l|}{ Age, years } \\
\hline$\geq 70$ (reference group) & 18 & & & \\
\hline $40-49$ & 24.1 & & & \\
\hline $50-69$ & 42 & & & \\
\hline \multicolumn{5}{|l|}{ Education } \\
\hline Not a college graduate (reference group) & 84.1 & & & \\
\hline College graduate & 15.9 & & & \\
\hline \multicolumn{5}{|l|}{ Income } \\
\hline$<\$ 20,000$ & 25.5 & & & \\
\hline$\$ 20,000-\$ 44,999$ & 32.9 & & & \\
\hline$\$ 45,000-\$ 74,999$ & 20.7 & & & \\
\hline$\geq \$ 75,000$ (reference group) & 21 & & & \\
\hline \multicolumn{5}{|l|}{ Perceived health status } \\
\hline Poor & 6.5 & & & \\
\hline Fair & 22.9 & & & \\
\hline Good & 41.3 & & & \\
\hline Very good & 22.6 & & & \\
\hline Excellent & 6.7 & & & \\
\hline Church attendance yearly & 3.07 & 4.827 & 0 & 30 \\
\hline \multicolumn{5}{|l|}{ Access to health care } \\
\hline There is no place to go & 5.6 & & & \\
\hline There is more than one place & 94.4 & & & \\
\hline
\end{tabular}

Note: $n=377$ is based on weighted data from the CDC Nutritional Health and Examination Survey.

Abbreviations: CDC, Centers for Disease Control and Prevention; Max, maximum; Min, minimum; SD, standard deviation.

$(n=286 ; 75.9 \%)$ and did not have a college degree $(n=317$; $84.1 \%)$. Income was reported as follows: $<\$ 20,000(\mathrm{n}=96$; $25.5 \%) ; \$ 20,000-\$ 49,999$ (32.9\%); \$45,000-\$74,999 $(\mathrm{n}=78 ; 20.7 \%) ; \geq \$ 75,000(\mathrm{n}=79 ; 21 \%)$. Most participants rated their perceived health as "good" (good $=41.3 \%$, fair $=22.9 \%$, very good $=22.6 \%$, excellent $=6.7 \%$, and poor $=6.5 \%)$. Marital status was recorded as not married $(n=172$; $45.6 \%)$ and married $(n=202 ; 54.4 \%)$. Participants attended church yearly an average of 3 days per year $(\mathrm{M}=3.07$; SD =4.827). Access to a health facility was affirmed by the participants response of yes access to a health care facility $(\mathrm{n}=355 ; 94.4 \%)$; most had undergone (PSA test, $\mathrm{n}=292$; $77.5 \%$; DRE, $n=263 ; 69.8 \%$ ). Cross tabulations were performed among each covariate and the outcome variables, the DRE and the PSA test. Results for the cross tabulations are listed in Tables 2 and 3 for church attendance and the DRE and PSA test. Cross tabulations for intrapersonal and community variables and the DRE and PSA test are listed in
Table 2 Cross tabulations yearly church attendance and DRE $(n=377)$

\begin{tabular}{lll}
\hline Variable & DRE & \\
\hline & No & Yes \\
\hline Church attendance yearly, days & & \\
$<30$ & 48 & 153 \\
30 to $<100$ & 14 & 81 \\
$\geq 100$ & 10 & 29 \\
\hline
\end{tabular}

Note: $n=377$ is based on weighted data from the CDC Nutritional Health and Examination Survey.

Abbreviations: CDC, Centers for Disease Control and Prevention; DRE, digital rectal exam.

Table 3 Cross tabulations yearly church attendance and PSA test $(\mathrm{n}=377)$

\begin{tabular}{lll}
\hline Variable & PSA & \\
\hline & No & Yes \\
\hline Church attendance yearly, days & & \\
$\quad<30$ & 54 & 166 \\
30 to $<100$ & 25 & 86 \\
$\geq 100$ & 5 & 40 \\
\hline
\end{tabular}

Note: $\mathrm{n}=377$ is based on weighted data from the CDC Nutritional Health and Examination Survey.

Abbreviations: CDC, Centers for Disease Control and Prevention; PSA, prostatespecific antigen.

Figures 1 and 2. There were similar results for AA males that received the DRE and the PSA test among the intrapersonal and community covariates.

\section{DRE logistic regression model}

Results from each of the two logistic regression models are presented in Tables 4 and 5, respectively. The first model regressed the DRE independently on the intrapersonal covariates (age, education, income, perceived health status, and marital status) and the community covariates (church attendance and access to health care) to identify which factors were associated with a greater likelihood of receiving PCS. The Hosmer and Lemeshow test indicated a good overall model fit $(P>0.05)$. Education level, was associated with receiving a PCS $\left(b=-1.930, \mathrm{e}^{\mathrm{B}}=0.145,95 \% \mathrm{CI}^{\mathrm{B}}[0.032,0.655]\right.$, $P<0.05)$; indicating AA males without a college degree were less likely to receive a DRE compared to AA males that possessed a college degree. Lack of access to a health care facility was associated with receiving the DRE $(b=-1.170$, $\left.\mathrm{e}^{\mathrm{B}}=0.310,95 \% \mathrm{CI} \mathrm{e}^{\mathrm{B}}[0.097,0.988], P<0.05\right)$ wherein compared to AA males with access to health, AA males without access to health care were least likely to receive a DRE. There were no associations between AA males receiving PCS and age, income level, marital status, perceived health status, or church attendance. 


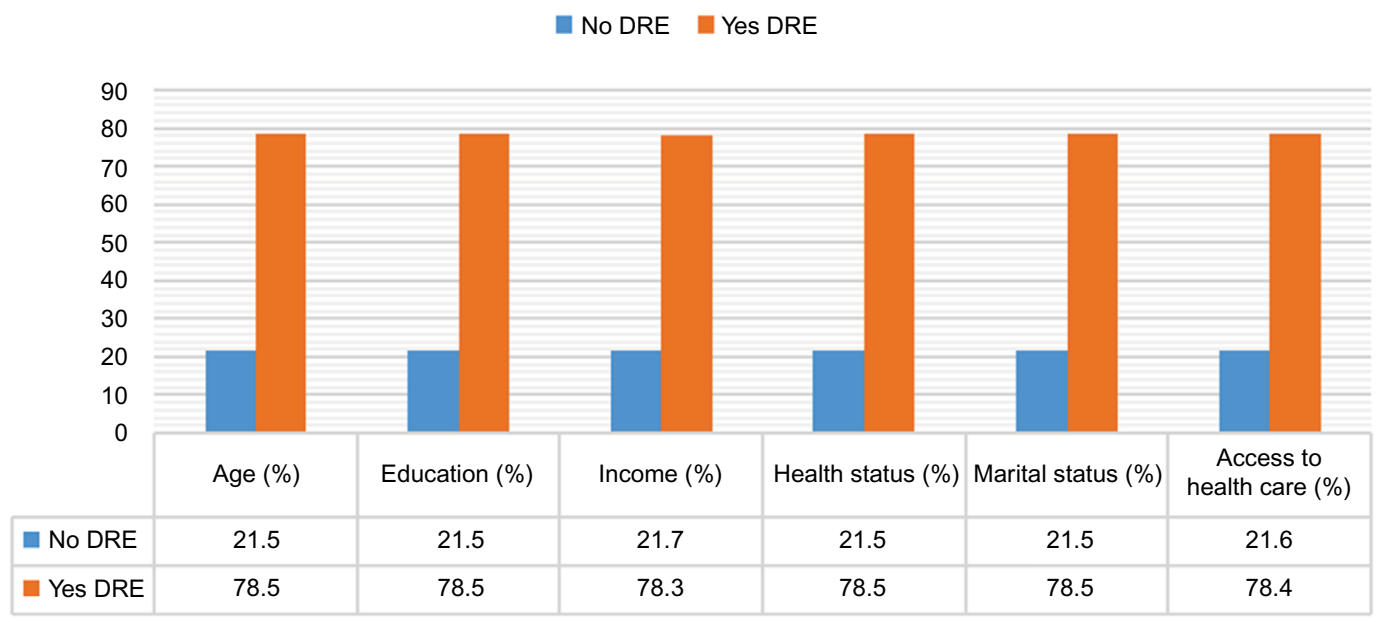

Figure I Cross tabulation of intrapersonal variables and the DRE. Abbreviation: DRE, digital rectal exam.

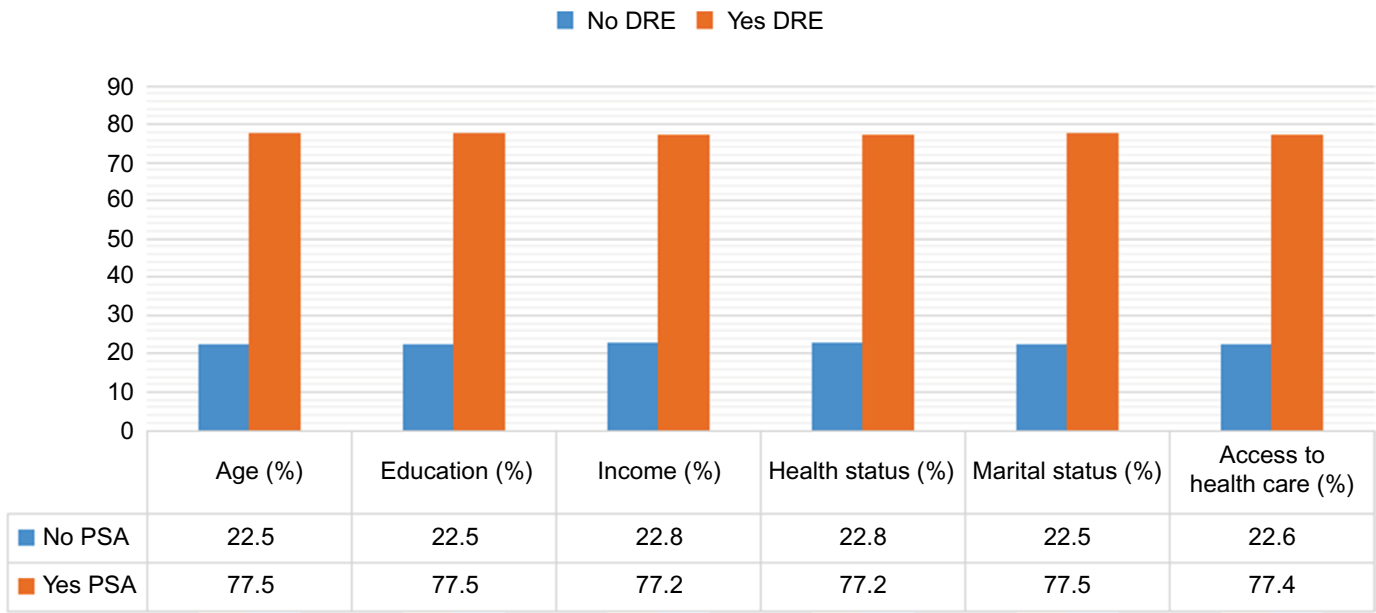

Figure 2 Cross tabulation of intrapersonal variables and the PSA test. Abbreviation: PSA, prostate-specific antigen.

\section{PSA test logistic regression model}

In the second regression model, the PSA test was regressed separately on the previous intrapersonal covariates (age, education, income, perceived health status, and marital status) and the community covariates (church attendance and access to health care) to determine which factors were associated with higher PCS rates (aim 1). The Hosmer and Lemeshow test indicated a good overall model fit $(P>0.05)$. Associations with receiving the PSA test were reported for all age groups $40-49$ years $\left(b=1.251, \mathrm{e}^{\mathrm{B}}=3.495,95 \% \mathrm{CI} \mathrm{e}^{\mathrm{B}}[1.355,9.015]\right.$, $P<0.05), 50-69$ years $\left(\mathrm{b}=0.778, \mathrm{e}^{\mathrm{B}}=2.176,95 \% \mathrm{CI}^{\mathrm{B}}[1.089\right.$, $4.348], P<0.05)$ therefore, the age groups of $40-49$ and 50-69 years when compared to the age group of $\geq 70$ years were more likely to receive the PSA test. Church attendance was associated with receiving a PSA test $\left(\mathrm{b}=0.009, \mathrm{e}^{\mathrm{B}}=1.009,95 \% \mathrm{CI}\right.$ $\left.\mathrm{e}^{\mathrm{B}}[1.001,1.017], P<0.05\right)$. AA males who attended church were more likely to receive a PSA test. Education, income, perceived health status, marital status, and access to health care were not associated with AA males receiving a PSA test.

\section{Discussion}

This study delineated the association between intrapersonal and community factors for receiving PCS in a populationbased sample of AA males aged $\geq 40$ years from a national data set within the US. The findings supported an association for education and access to health care with receiving the DRE. However, results were in contrast to the literature that indicated age was associated with AA males receiving the DRE. In spite of the controversy surrounding PCS, AA males $>40$ to 49 years of age were more likely to receive PCS, relative to their older counterparts.

The TPB was selected based on the assumption of predicting behavior based on an individual's internal and external beliefs. As in the TPB, the goal of the study was examining 
Table 4 Regression of intrapersonal and community variables on digital rectal exam

\begin{tabular}{|c|c|c|c|c|}
\hline Variables & $\mathbf{b}$ & SE & $\mathbf{e}^{\mathrm{B}}$ & $95 \% \mathrm{Cl} \mathrm{e}^{\mathrm{B}}$ \\
\hline \multicolumn{5}{|l|}{ Age, years } \\
\hline $40-49$ & -0.920 & 0.489 & 0.398 & $0.153,1.038$ \\
\hline $50-69$ & -0.024 & 0.423 & 0.977 & $0.419,2.278$ \\
\hline \multicolumn{5}{|l|}{ Education } \\
\hline Not a college graduate & $-1.930 *$ & 0.768 & 0.145 & $0.032,0.655$ \\
\hline \multicolumn{5}{|l|}{ Income } \\
\hline$<\$ 20,000$ & -1.446 & 0.594 & 0.235 & $0.074,0.754$ \\
\hline$\$ 20,000-\$ 44,999$ & -1.189 & 0.554 & 0.305 & $0.103,0.902$ \\
\hline$\$ 45,000-\$ 74,000$ & -0.856 & 0.582 & 0.425 & $0.136,1.329$ \\
\hline \multicolumn{5}{|l|}{ Perceived health status } \\
\hline Poor & $-2.04 \mid$ & 1.230 & 0.130 & $0.012,1.148$ \\
\hline Fair & -2.268 & 1.091 & 0.103 & $0.012,0.878$ \\
\hline Good & -1.951 & 1.070 & 0.142 & $0.017,1.158$ \\
\hline Very good & -1.940 & 1.087 & 0.144 & $0.017,1.211$ \\
\hline \multicolumn{5}{|l|}{ Marital status } \\
\hline Not married & -0.331 & 0.340 & 0.718 & $0.369,1.400$ \\
\hline Church attendance yearly & -0.002 & 0.002 & 0.998 & $0.097,0.988$ \\
\hline \multicolumn{5}{|l|}{ Access to health care facility } \\
\hline $\begin{array}{l}\text { No access to health care } \\
\text { facility }\end{array}$ & $-1.170 *$ & 0.591 & 0.310 & $0.097,0.988$ \\
\hline
\end{tabular}

Notes: $* P<0.05$.

Abbreviations: b, coefficient; $\mathrm{e}^{\mathrm{B}}$, exponential coefficient; SE, standard error; $95 \%$ $\mathrm{Cl} \mathrm{e}^{\mathrm{B}}, 95 \%$ confidence interval of exponential coefficient.

Table 5 Regression of intrapersonal and community variables on the prostate-specific antigen test $(n=377)$

\begin{tabular}{|c|c|c|c|c|}
\hline Variables & $\mathbf{b}$ & SE & $\mathrm{e}^{\mathrm{B}}$ & $95 \% \mathrm{Cl} \mathrm{e}^{\mathrm{B}}$ \\
\hline \multicolumn{5}{|l|}{ Age, years } \\
\hline $40-49$ & $1.25 I^{*}$ & 0.484 & 3.495 & $1.355,9.015$ \\
\hline $50-69$ & $0.778 *$ & 0.353 & 2.176 & $1.089,4.348$ \\
\hline \multicolumn{5}{|l|}{ Education } \\
\hline Not a college graduate & 0.430 & 0.443 & 1.538 & $0.646,3.661$ \\
\hline \multicolumn{5}{|l|}{ Income } \\
\hline$<\$ 20,000$ & $-1.27 \mid$ & 0.579 & 0.280 & $0.090,0.872$ \\
\hline$\$ 20,000-\$ 44,999$ & -1.102 & 0.522 & 0.332 & $0.119,0.923$ \\
\hline$\$ 45,000-\$ 74,000$ & -0.457 & 0.551 & 0.633 & $0.215,1.866$ \\
\hline \multicolumn{5}{|l|}{ Perceived health status } \\
\hline Poor & -0.327 & 0.986 & 0.721 & $0.104,4.981$ \\
\hline Fair & -0.291 & 0.675 & 0.748 & $0.199,2.810$ \\
\hline Good & -0.451 & 0.624 & 0.637 & $0.187,2.166$ \\
\hline Very good & -0.932 & 0.637 & 0.394 & $0.113,1.373$ \\
\hline \multicolumn{5}{|l|}{ Marital status } \\
\hline Not married & 0.591 & 0.342 & 1.806 & $0.923,3.531$ \\
\hline Church attendance yearly & $0.009 *$ & 0.004 & 1.009 & $1.001,1.017$ \\
\hline \multicolumn{5}{|l|}{ Access to health care facility } \\
\hline $\begin{array}{l}\text { No access to health care } \\
\text { facility }\end{array}$ & 0.474 & 0.801 & 1.607 & $0.334,7.724$ \\
\hline
\end{tabular}

Notes: $* P<0.05$.

Abbreviations: b, coefficient; $\mathrm{e}^{\mathrm{B}}$, exponential coefficient; SE, standard error; $95 \%$ $\mathrm{Cl} \mathrm{e}^{\mathrm{B}}, 95 \%$ confidence interval of exponential coefficient.

the occurrence of a behavior, PCS, based on the presence or absence of internal and external factors. The factors within the current study support and align with the constructs of the TPB, attitude, subjective norms, and perceived behavioral control. Attitude is a construct within the TPB, which was not analyzed in the current study. However the stigma, anxiety, and threat to masculinity regarding $\mathrm{PCa}$ and PCS were indicated within the literature as examples that were barriers for AA males to receive PCS.

Age was classified as a subjective norm of the TPB and was significantly associated with AA males receiving the PSA test. Similarly, education was also classified as a subjective norm of the TPB and was significantly associated with AA males receiving only the DRE. Despite the literature indicating spouses, family members, and friends as motivators for AA males to receive PCS, the current study did not produce those findings. Perhaps the lack of association among spouses, family members, and friends; and PCS could be attributed to the sample possibly comprised of AA males, which abide by traditional masculine roles. In general, males that abide by a traditional masculine role do not seek the advice or are not influenced by others to adopt behaviors. Additionally, the lack of association church attendance was a factor within the study that was indicated as a subjective norm and was found to be significantly associated with the PSA test. The construct of perceived behavioral control was delineated by the factor of perceived health status. Overall, the TPB provided a sound theoretical framework, which allowed the examination of internal and external factors that are relevant in the lives of AA males to receive or decline PCS.

Compared to males aged $\geq 70$, younger age groups, 40-49 years $\left(\mathrm{b}=1.251, \mathrm{e}^{\mathrm{B}}=3.495,95 \% \mathrm{CI} \mathrm{e}^{\mathrm{B}}[1.355,9.015]\right.$, $P<0.05)$ and $50-69$ years $\left(\mathrm{b}=0.778, \mathrm{e}^{\mathrm{B}}=2.176,95 \% \mathrm{CI} \mathrm{e}^{\mathrm{B}}\right.$ $[1.089,4.348], P<0.05)$ was positively associated with receiving the PSA test. An association between age and PCS has been affirmed in previous studies. ${ }^{20-22}$ However, age was not associated with receiving the DRE. The lack of association among age and the DRE may attributed to the sensitive nature of administering the DRE. Previous research among AA males indicated $\mathrm{PCa}$ as a threat to manhood and the males believed that if you are not homosexual you should not receive the DRE. ${ }^{30}$ Within the current study, the younger age groups may not have felt a sense of embarrassment or shame with receiving the blood test, PSA test, as opposed to the DRE. Despite studies indicating education as a predictor for receiving a PCS, education was only associated with the DRE. ${ }^{7,22}$ A negative association existed among education and the PSA test, which indicated that AA males without a college degree were less likely to receive a PSA test compared to AA males with a college degree $\left(b=-1.930, \mathrm{e}^{\mathrm{B}}=0.145,95 \%\right.$ CI $\mathrm{e}^{\mathrm{B}}$ [0.032, 0.655], $\left.P<0.05\right)$. Additional studies focused on provider-patient interactions, which will assist to better understand how conversation about PCa risk affects decision making about PSA testing among AA males. Nurses are in 
a unique role to establish trust and begin conversations to promote informed decision making for PCS.

Income was not associated with AA males receiving the DRE or the PSA test. This finding is in contrast to several studies that reported an association between income and PCS. ${ }^{6,15,27}$ Perceived health status was not associated with PCS in the current study. The finding was not supported by literature that reported AA males with higher positive health values were more likely to receive PCS. ${ }^{42}$ The majority of participants in this study described their health as "good" versus "very good" or "excellent"; it is possible that a higher rating would have been associated with increased preventive health behaviors, such as PCS. Self-awareness of health and well-being has been identified as a correlate of PCS. ${ }^{34}$ It may be that individuals with higher health values may also seek knowledge of personal health risks and to engage in preventive health behaviors. Marital status was not associated with receiving PCS, which was also in contrast to studies that reported spouses as influencing males to receive PCS. ${ }^{3,15,24,28}$ One notion could be the sample of AA males within the data set may uphold patriarchal values in which the male head of the household makes the decisions with minimum input from the rest of family members.

Church attendance reported a positive association with AA males receiving a PSA test $\left(\mathrm{b}=0.009, \mathrm{e}^{\mathrm{B}}=1.009,95 \% \mathrm{CI}\right.$ $\mathrm{e}^{\mathrm{B}}$ [1.001, 1.017], $\left.P<0.05\right)$. Literature identifies the church as a salient factor in the lives of $\mathrm{AAs}^{20,41,43}$ and a valuable resource for health programs based in the community. The influence of the church in reducing health disparities highlights the value of church involvement as a vital resource for promoting health and reducing health disparities in the AA population. The propensity for AAs to attend church services on a regular basis presents opportunities for the dissemination of information on preventive services and support for PCS. ${ }^{40}$ Furthermore, the significant negative association of access to health care with DRE suggests that the availability of health care could be a source of PCa information for screening eligible AA males. AA males without access to health care were less likely to receive the DRE compared to AA males with access to health care $\left(b=-1.170, \mathrm{e}^{\mathrm{B}}=0.310,95 \% \mathrm{CI} \mathrm{e}^{\mathrm{B}}\right.$ $[0.097,0.988], P<0.05)$. Previous studies demonstrated that increased knowledge about PCa risks and screening options facilitates informed decision making and helps reduce disparities among high-risk minority males. ${ }^{11}$

Clinics located within the community that offer PCS during nontraditional hours and at locations that are easily accessible for AA males was not examined in this study; however, those venues are potentially another source for increasing access to care. Additional measures must be taken to provide access to health care for underserved populations. A lack of access to health care limits the availability of health care providers to perform the DRE. This could explain the lack of association among age and receiving the DRE in the current study. The PSA test does not require the privacy or time necessary for administering the DRE and it can be considered as less intimate compared to receiving the DRE. A health care facility is essential for administering the DRE, whereas the PSA test can be administered at churches, barbershops, and various locations within a community. However, without access to health care facilities for health care providers to administer the DRE, AA males will go unscreened and be at risk for undiagnosed PCa at an advanced stage. The significant results for age and receiving the PSA test may reflect a lack of health care facilities with health care providers capable of administering the DRE. In view of the confusion around PCS guidelines and cultural barriers rooted in mistrust of the medical community, culturally sensitive psychosocial interventions situated within the AA church community have the potential to raise $\mathrm{PCa}$ awareness and informed decision making regarding PCS. Nurses can assist with increasing the confidence among the AA population regarding informed decision making through an understanding of their individual risk factors and family history. Effective patient-centered communication is pertinent for diminishing misinformation and confusion related to health topics and regarding a reduction in health disparities it is a vital aspect for all nurses to employ.

\section{Limitations}

The study has several potential limitations. Despite the oversampling for AA participants, the data set still contained a small sample size of AA males and hence, the findings may not be generalizable to all AA males over 40 years of age. Another limitation was the outcome variable that the DRE was obtained by self-report. Hence, the information was not verified by medical records. There was a possibility that this self-report data was not accurately reported by the participants within the NHANES data set. Also despite the detailed NHANES questionnaire, there was insufficient data pertaining to levels of trust in health care providers to determine if these variables were pertinent in predicting PCS.

\section{Conclusion}

There were similarities and differences among the PCS preferences for the sample of AA males examined in the current study. Nursing can be a guiding force to elevate the uncertainty 
and educate vulnerable populations surrounding the decision to receive or decline PCS. Public health policy and programs that promote $\mathrm{PCa}$ awareness and informed decision making among AA males should target younger males regarding risk factors and focus on increasing access to health services that include PCS services. Community nurses serve in an influential role to promote awareness of PCa and PCS. Specialized training, which is culturally competent, should be explored to discuss the sensitive topic of PCS among AA males. Nurses are trained to effectively communicate and interact with diverse populations. Through continued education using an evidence-based approach, the health disparity of PCa among AA males in the US can be reduced.

\section{Disclosure}

The authors report no conflicts of interest in this work.

\section{References}

1. Howlader N, Noone, AM, Krapcho M, et al. SEER Cancer Statistics Review, 1975-2011. Bethesda, MD: National Cancer Institute. Available from: http://seer.cancer.gov/csr/1975_2011/. Accessed July 18, 2015.

2. Hsing A, Tsao L, Devesa S. International trends and patterns of prostate cancer incidence and mortality. Int J Cancer. 2000;85(1):60-67.

3. Jones RA, Steeves R, Williams I. Family and friend interactions among African-American mens deciding whether or not to have a prostate cancer screening. Urol Nurs. 2010;30(3):189-193.

4. Lim LS, Sherin K; ACPM Prevention Practice Committee. Screening for prostate cancer in U.S. mens ACPM position statement on preventive practice. Am J Prev Med. 2008;34(2):164-170.

5. Siegel R, Naishadham D, Jemal A. Cancer statistics, 2013. CA Cancer J Clin. 2013;63(1):11-30.

6. Carpenter WR, Godley PA, Clark JA, et al. Racial differences in trust and regular source of patient care and the implications for prostate cancer screening use. Cancer. 2009;115(21):5048-5059.

7. Haque R, Van Den Eeden SK, Jacobsen SJ, et al. Correlates of prostatespecific antigen testing in a large multiethnic cohort. Am J Manag Care. 2009;15(11):793-799.

8. Woods VD, Montgomery SB, Herring RP. Recruiting Black/African American mens for research on prostate cancer prevention. Cancer. 2004;100(5):1017-1025

9. American Cancer Society Task Force Recommends against Routine Prostate Cancer Screening. Available from: http://www.cancer.org/ Cancer/news/News/task-force-recommends-against-routine-prostatecancer-screenin. Accessed July 8, 2012.

10. Carlsson S, Vickers AJ, Roobol M, Eastham J, Scardino P, Lilja H, Hugosson J. Prostate cancer screening: facts, statistics, and interpretation in response to the US Preventive Services Task Force Review. J Clin Oncol. 2012;30(21):2581-2584.

11. Sajid S, Kotwal AA, Dale W. Interventions to improve decision making and reduce racial and ethnic disparities in the management of prostate cancer: a systematic review. J Gen Intern Med. 2012;27(8):1068-1078.

12. Schröder FH, Hugosson J, Roobol MJ, et al. Screening and prostatecancer mortality in a randomized European study. $N$ Engl J Med. 2009;360(13):1320-1328.

13. Djulbegovic M, Beyth RJ, Neuberger MM, Stoffs TL, Vieweg J, Djulbegovic B, Dahm P. Screening for prostate cancer: systematic review and meta-analysis of randomized controlled trials. BMJ. 2010;341:c4543.

14. Ajzen I. The theory of planned behavior. Organ Behav Hum Decis Process. 1991;50(2):179-211.
15. Papatsoris A, Anagnostopoulos F. Prostate cancer screening behaviour. Public Health. 2009;123(1):69-71.

16. Naccarato AM, Reis LO, Matheus WE, Ferreira U, Denardi F. Barriers to prostate cancer screening: psychological aspects and descriptive variables - is there a correlation? Aging Male. 2011;14(1):66-71.

17. Courtney WH. Key determinants of the health and well-being of mens and boys. Int J Mens Health. 2003;2(1):1-30.

18. Webb CR, Kronheim L, Williams JE, Hartman TJ. An evaluation of the knowledge, attitudes, and beliefs of African-American mens and their female significant others regarding prostate cancer screening. Ethn Dis. 2006;16(1):234-238.

19. Sussman L, Robins L, Earls, F. Treatment-seeking for depression by black and white Americans. Soc Sci Med. 1987;24(3):187-196.

20. McFall SL, Davila M. Gender, social ties, and cancer screening among elderly persons. J Aging Health. 2008;20(8):997-1011.

21. Smith-McLallen A, Fishbein M. Predicting intentions to engage in cancer prevention and detection behaviors: examining differences between Black and White adults. Psychol Health Med. 2009;14(2):180-189.

22. Sieverding M, Matterne U, Ciccarello L. What role do social norms play in the context of mens's cancer screening intention and behavior? Application of an extended theory of planned behavior. Health Psychol. 2010;29(1):72-81.

23. Hevey D, Pertl M, Thomas K, Maher L, Chuinneagáin SN, Craig A. The relationship between prostate cancer knowledge and beliefs and intentions to attend PSA screening among at-risk mens. Patient Educ Couns. 2009;74(2):244-249.

24. Drake BF, Shelton RC, Gilligan T, Allen JD. A church-based intervention to promote informed decision making for prostate cancer screening among African American mens. J Natl Med Assoc. 2010;102(3):164-171.

25. Woods VD, Montgomery SB, Herring RP, Gardner RW, Stokols D. Social ecological predictors of prostate-specific antigen blood test and digital rectal examination in black American mens. J Natl Med Assoc. 2006;98(4):492-504.

26. Satia JA, Galanko JA. Demographic, behavioral, psychosocial, and dietary correlates of cancer screening in African Americans. J Health Care Poor Underserved. 2007;18(4 Suppl):146-164.

27. Chiu BC, Anderson JR, Corbin D. Predictors of prostate cancer screening among health fair participants. Public Health. 2005;119(8):686-693.

28. Carter VL, Tippett F, Anderson DL, Tameru B. Increasing prostate cancer screening among African American mens. J Health Care Poor Underserved. 2010;21(3 Suppl):91-106.

29. Peterson J, Atwood JR, Yates B. Key elements for church-based health promotion programs: outcome-based literature review. Public Health Nurs. 2002;19(6):401-411.

30. Guttman C. Awareness of PCa risk low among urban blacks. Urol Times. 2001;29(3):8.

31. Richardson LD, Norris M. Access to health and health care: how race and ethnicity matter. Mt Sinai J Med. 2010;77(2):166-177.

32. Talcott JA, Spain P, Clark JA, et al. Hidden barriers between knowledge and behavior: the North Carolina prostate cancer screening and treatment experience. Cancer. 2007;109(8):1599-1606.

33. Wray R, McClure S, Vijaykumar S, Smith C, Ivy A, Jupka K, Hess R. Changing the conversation about prostate cancer among African Americans: results of formative research. Ethn Health. 2009;14(1):27-43.

34. Sanchez MA, Bowen DJ, Hart A, Spigner C. Factors influencing prostate cancer screening decisions among African American mens. Ethn Dis. 2007;17(2):374-380.

35. Tannor BB, Ross L. Physician-patient discussions about prostate-specific antigen test use among African-American mens. J Natl Med Assoc. 2006;98(4):532-538.

36. Lehto RH, Song L, Stein KH, Coleman-Burns P. Factors influencing prostate cancer screening in African American Men. West $J$ Nurs Res. 2010;32(6):779-793.

37. Campbell MK, Hudson MA, Resnicow K, Blakeney N, Paxton A, Baskin M. Church-based health promotion interventions: evidence and lessons learned. Annu Rev Public Health. 2007;28:213-234. 
38. Weinrich S, Holdford D, Boyd M, et al. Prostate cancer education in African American churches. Public Health Nurs. 1998;15(3):188-195.

39. Johnson KS, Elbert-Avila K, Tulsky JA. The influence of spiritual beliefs and practices on the treatment preferences of African Americans: a review of the literature. J Am Geriatr Soc. 2005;53(4):711-719.

40. Newton, F. Americans' church attendance inches up in 2010. Gallup. Available from: http://www.gallup.com/poll/141044/americans-churchattendance-inches-2010.aspx. Accessed July 29, 2013.

41. Chatters LM, Taylor RJ, Lincoln KD, Schroepfer T. Patterns of informal support from family and church members among African Americans. J Black Stud. 2002;33(1):66-85.

42. Eng E, Hatch J, Callan A. Institutionalizing social support through the church and into the community. Health Educ Q. 1985;12(1):81-92.
43. Krause N. Church-based social support and health in old age: exploring variations by race. J Gerontol B Psychol Sci Soc Sci. 2002;57(6): S332-S347.

44. Holt CL, Clark EM, Roth D, et al. Development and validation of instruments to assess potential religion-health mechanisms in an African American population. J Black Psychol. 2009;35(2):271-288.

45. Mitchell J. Examining the influence of social ecological factors on prostate cancer screening in urban African-American mens. Soc Work Health Care. 2011;50(8):639-655.

46. Ukoli FA, Patel K, Hargreaves M, et al. A tailored prostate cancer education intervention for low-income African Americans: impact on knowledge and screening. J Health Care Poor Underserved. 2013;24(1): 311-331.
Nursing: Research and Reviews

\section{Publish your work in this journal}

Nursing: Research and Reviews is an international, peer-reviewed, open access journal publishing original research, reports, reviews and commentaries on all aspects of nursing and patient care. These include patient education and counseling, ethics, management and organizational issues, diagnostics and prescribing, health outcomes, economics and
Dovepress

resource management, improving patient safety in all settings. The manuscript management system is completely online and includes a very quick and fair peer-review system. Visit http://www.dovepress. com/testimonials.php to read real quotes from published authors. 